\title{
DANOS CELULARES CAUSADOS PELA ÁGUA AVALIADOS PELO BIOENSAIO DE Allium cepa
}

\author{
CELL DAMAGE CAUSED BY WATER EVALUATED BY Allium cepa \\ BIOASSAY
}

\author{
Varaschini, FR ${ }^{1}$, Balsanello, $\mathrm{RL}^{1}$, Retuci, $\mathrm{VS}^{1}$, Souza-Franco, GM de ${ }^{1}$, Moura, $\mathrm{AC}^{1}$, Soares, \\ $\mathrm{IA}^{1}$. \\ Afiliações dos autores: 1- Universidade Federal da Fronteira Sul, Campus Realeza/Paraná. \\ Endereço do autor de correspondência: Rua: Edmundo Gaievski, número: 1000, centro, Realeza Paraná, Brasil. CEP:85770-000 e-mail: \\ izabel.soares@uffs.edu.br
}

\begin{abstract}
Resumo: Este estudo teve como objetivo avaliar possíveis danos celulares causados pela água de poços artesianos usando o sistema de teste Allium cepa. As amostras analisadas foram obtidas no município de Realeza, sudoeste do Paraná. Para cada tratamento, cinco bulbos de Allium cepa foram postos para germinar durante 72 horas e como controle negativo água destilada e controle positivo solução aquosa de sulfato de cobre $0,0006 \%$. Posteriormente, as raízes foram submetidas ao protocolo de Feulgen com modificações, para a confecção das lâminas e verificação de alterações nos valores de Índice Mitótico e Alterações Cromossômicas. Para testar a diferença entre os tratamentos foi utilizada a análise de variância para dados paramétricos (Anova) e o teste de Tukey com confiabilidade de 5\%. Através do bioensaio de citotoxicidade com Allium cepa, os resultados indicaram que as amostras de água foram capazes de causar danos ao DNA. Os valores para índice mitótico foram menores para P1 e P2 sugerindo citotoxicidade. Os efeitos de genotoxicidade e mutagenicidade foram identificados nas amostras P1, P2 e genotoxicidade para P3. Os resultados observados nesta pesquisa permitiram concluir que através do bioensaio utilizando o sistema teste Allium cepa foram detectados efeitos genotóxicos, citotóxicos e mutagênicos para as amostras testadas.
\end{abstract}

Palavras-chave: agua; mutagenicidade; sistema-teste Allium cepa; alterações cromossômicas.

\begin{abstract}
This study aimed to evaluate possible cellular damage caused by water from artesian wells using the Allium cepa test system. For each treatment, five bulbs of Allium cepa were germinated for 72 hours and distilled water was used as the control. Subsequently, the roots were submitted to the Feulgen protocol with modifications, for the preparation of the slides and verification of changes in the values of Mitotic Index and Chromosomal Alterations. To test the difference between the treatments, the analysis of variance for parametric data (Anova) and the Tukey test with reliability of 5\% were used. Through the cytotoxicity bioassay with Allium cepa, the results indicated that the water samples were able to cause damage to the DNA. Mitotic index values were lower for P1 and P2 suggesting cytotoxicity. The effects of genotoxicity and mutagenicity were identified in samples P1, P2 and genotoxicity for P3. The results observed in this study allowed us to conclude that genotoxic, cytotoxic and mutagenic effects were detected through the bioassay using the Allium cepa test system for the tested samples.
\end{abstract}

Keywords: water; mutagenicity; system-test Allium cepa; chromosomes alterations. 
Introdução

A água é elemento essencial para o desenvolvimento e manutenção da vida. Dentre os recursos naturais, constitui-se como o mais importante para a subsistência das espécies, que dependem da sua disponibilidade para satisfazer as necessidades básicas ${ }^{1}$. Porém, apesar de essencial a vida, sua utilização vem sendo ameaçada por constantes contaminações, o que tem preocupado o consumo em sua condição natural ${ }^{2,3}$

Na tentativa de minimizar os efeitos de contaminantes, uma alternativa é a captação e o consumo de águas subterrâneas, usufruindo dos lençóis freáticos para o abastecimento de propriedades rurais e de algumas regiões urbanas $^{4}$

Entretanto, no meio rural as principais formas de abastecimento de água são fontes e poços rasos. Fato preocupante, pois na maioria das vezes esses meios se encontram em condições inadequadas de preservação, consequência da interferência desenfreada do ser humano, por ações como: desmatamentos das encostas e das matas ciliares, contaminação dos cursos hídricos pelos resíduos industriais, deposição inadequada de esgoto e lixo doméstico nos solos e por contaminantes advindos de atividades agrícolas ${ }^{5,6}$

Ainda é importante salientar que, das lavouras muitos produtos utilizados têm recebido especial atenção devido aos efeitos negativos que promovem tanto ao ecossistema, quanto a saúde humana ${ }^{7}$
Todos esses fatores de contaminação contribuem para alterações na qualidade da água, afetando direta ou indiretamente, organismos que dela dependem, já que podem conter substâncias com propriedades mutagênicas, genotóxicas e citotóxicas que afetam a integridade genética dos seres vivos.

Para monitorar e estabelecer ações, é importante avaliar a qualidade da água, para isso técnicas que apresentam custo-benefício atraente são as mais adequadas. Dentre elas o sistemateste Allium cepa é frequentemente empregado para avaliar misturas complexas e efeitos genotóxicos. Esse teste evidencia um cenário de poluição ambiental e determinação dos efeitos de alguns químicos, pois a toxicidade pode ser observada pela inibição do crescimento das raízes, presença de raízes torcidas, efeitos adversos causados aos cromossomos e distúrbios no ciclo mitótico ${ }^{8,9}$

Nesse contexto, para avaliar se há potencial ecogenocitotóxico, amostras de águas de poços artesianos foram obtidas em uma região onde predomina a atividade agrícola, sendo o município de coleta, Realeza, localizado no sudoeste do Paraná.

\section{Métodos}

A obtenção das amostras de água para realização das análises ocorreu em três poços artesianos, numerados em P1, P2 e P3, escolhidos aleatoriamente, localizados na área rural no município de Realeza. As coletas foram feitas no ano de 2018 no período de março a julho totalizando três coletas por poço. $\mathrm{Na}$ área 
rural as coletas de água foram feitas em recipiente de plástico de $510 \mathrm{~mL}$, mantidas sobre refrigeração e levadas para o Laboratório de Biologia da Universidade Federal da Fronteira Sul, Campus Realeza, onde foram realizadas as análises ecogenotoxicológicas.

Os bulbos de cebolas da espécie A. cepa (diâmetro: 70 a $80 \mathrm{~mm}$ e peso: 150 a 180 g), com catafilos externos brancos, não germinados e saudáveis foram adquiridos comercialmente em supermercados em Realeza/Pr. Foram mantidos em local livre de umidade e ao abrigo de luz. E antes do teste, os catafilos externos secos foram removidos com bisturi, cuidando-se para que a área radicular não fosse danificada. Em seguida, os bulbos foram postos em água de torneira por duas horas para reduzir os efeitos de inibidores do brotamento e colocados para germinar em água filtrada não-clorada. Posteriormente, os bulbos enraizados foram distribuídos em recipientes contendo os tratamentos. Para o controle negativo utilizou-se água destilada e controle positivo solução aquosa de sulfato de cobre $0,0006 \%$, substância capaz de promover alterações celulares como aberrações cromossômicas e formação de micronúcleos. Para cada tratamento foi aplicado a uma série de cinco bulbos de cebola com três repetições. Após as radículas do controle atingirem o comprimento de 15 a $20 \mathrm{~mm}$, os bulbos dos tratamentos e controle são retirados, fixadas em Carnoy I a $4^{\circ} \mathrm{C}$ por pelo menos duas horas ${ }^{10}$

Foram confeccionadas três lâminas/bulbo/amostra de água. De cada lâmina, foram analisadas em "teste cego" 1000 células, perfazendo um total de 3000 células/bulbo/amostra. Para a avaliação dos efeitos citotóxicos, foram verificadas as alterações no Índice Mitótico (IM), calculado pelo número de células em divisão dividido pela soma do número das células em interfase e das células em divisão. Os efeitos genotóxicos foram analisados pelas anormalidades cromossômicas (AC) encontradas, considerando a porcentagem de irregularidades em metáfases, anáfases e presença de células com fragmentos cromossômicos e binucleações. As AC foram então fotodocumentadas.

Os dados obtidos quanto ao número de micronúcleos, proveniente da presença dos mesmos nas análises, os índices mitóticos e índices de anormalidades cromossômicas, foram submetidos à análise de variância (ANOVA), com nível de significância de 0,05 e posteriormente as médias foram comparadas por meio do Teste Tukey $(\mathrm{p}<0,05)$. As análises foram realizadas no software STATISTICA 6.0 (StatSoft, 2006).

\section{Resultados}

Para cada amostra foram analisadas nove mil células. Os resultados para o efeito de citotoxicidade avaliados pelo IM das amostras indicaram que P1 e P2 foram menores que o do controle negativo, com registro superior para o P3 (Tabela 1).

$\mathrm{Na}$ análise genotóxica constatou a presença de anormalidades cromossômicas, pela presença de células com danos, tais como: pontes anafásicas e telofásicas, anáfases com 
multipolaridades, c-metáfase, descompactação desigual da cromatina, prófases desorganizadas, metáfase anormal e anáfase anormal. (Tabela $1 \mathrm{e}$ Figura 1).

Para análise do potencial mutagênico as anomalias do tipo frequência de micronúcleos, stickines e outras não identificadas, indicaram a presença de contaminantes que promoveram mutagenicidade em células de Allium cepa. (Figura 1).

Ao comparar o controle negativo com o controle positivo os valores foram significativos, de acordo com o Teste de Dunnet $(\alpha=0,05$, $\mathrm{p}=0,022$ ), ou seja, a substância utilizada como controle positivo (sulfato de cobre $0,0006 \%$ ) conseguiu inibir o crescimento das raízes, enquanto que o controle negativo permitiu o seu crescimento, confirmando que esses controles são fonte confiável de comparação dos dados.

Tabela 1. Valores dos Índices Mitóticos (IM), Alterações Cromossômicas (AC) registrados para as amostras P1, P2, P3 e C (água destilada).

\begin{tabular}{|c|c|c|c|c|}
\hline & P1 & P2 & P3 & C \\
\hline IM (\%) & 6,2 & 8,2 & 22,7 & 8,9 \\
\hline AC (\%) & 3,1 & 4,3 & 3,4 & 1,6 \\
\hline
\end{tabular}

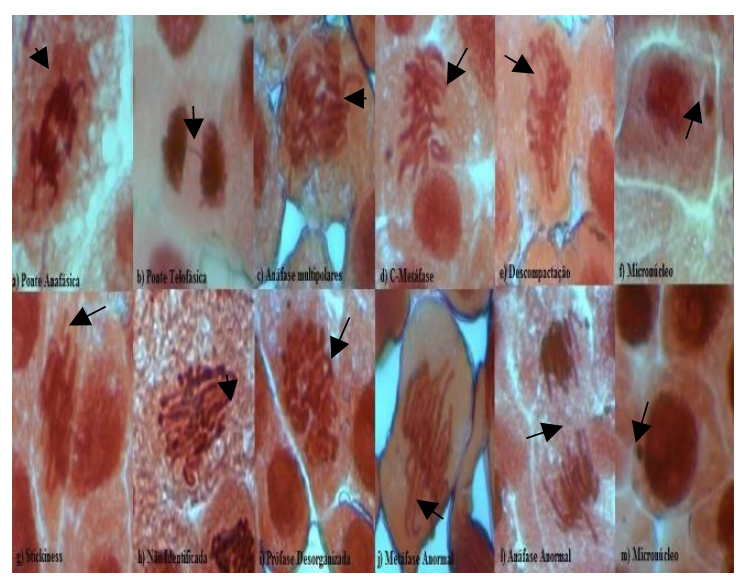

Figura 1. Alterações cromossômicas encontradas em células das raízes de Allium cepa tratadas com amostras de água de poços artesianos. a) pontes anafásica, b) ponte telofásica, c) anáfase multipolares, d) c-metáfase, e) descompactação desigual da cromatina. f) micronúcleos. g) stickiness, h) não-identificado, i) prófase desorganizada, j) metáfase anormal, l)nafase anormal, m)

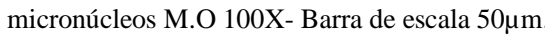

$\mathrm{O}$ resultado do teste estatístico não indicou diferença significativa entre as fases da mitose para as amostras P1 e P2, mas P3 diferiu significativamente (Figura 2). Para as anormalidades cromossômicas, a amostra P3 foi significativa para pontes metafásicas, alterações não identificadas, cromatina desorganizadas, prófase desorganizada, anáfase anormal, metáfase anormal. A amostra P1 indicou resultado significativo para a presença de micronúcleo e P2 significativo para descompactação da cromatina e micronúcleo (Figura 3). 


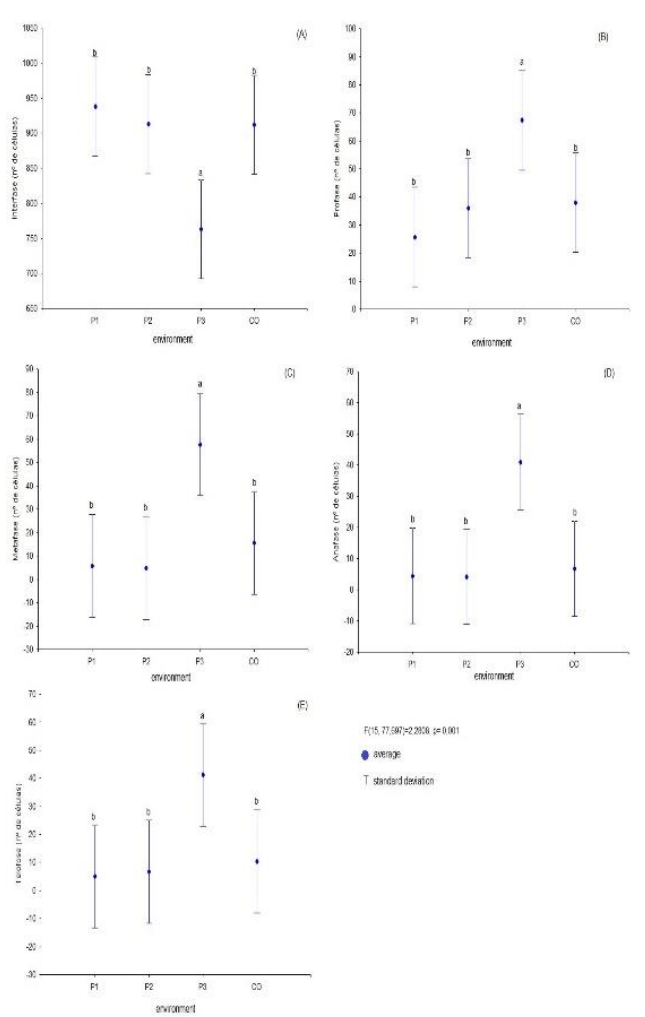

Figura 2. Frequência nas diferentes fases da mitose em células meristemáticas de raízes de $A$. серa desenvolvidas em diferentes amostras de agua de poços artesianos.

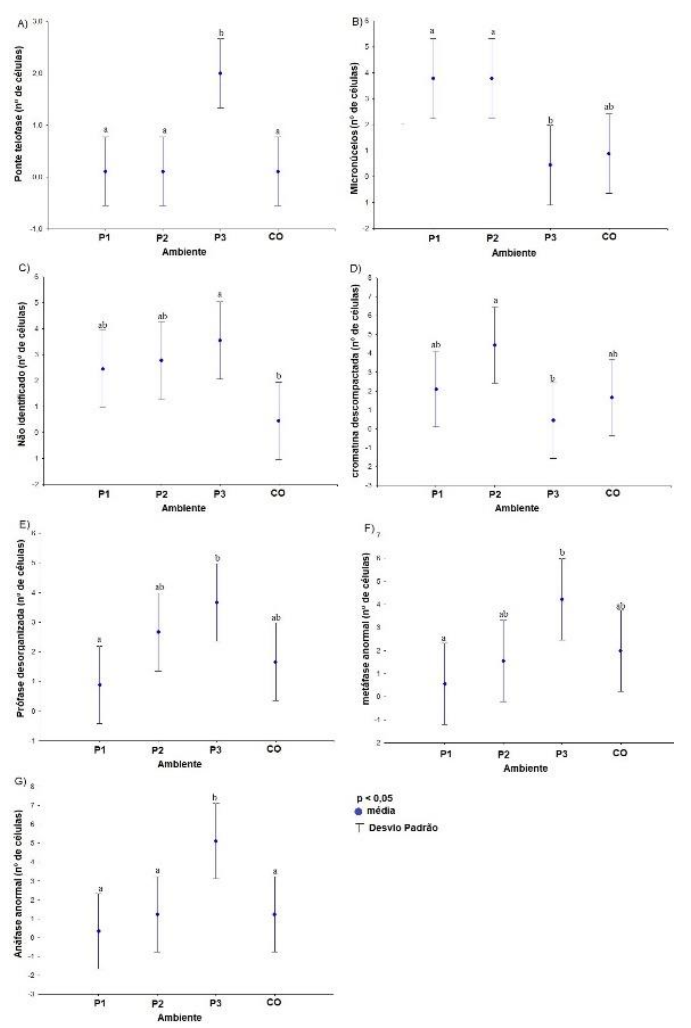

Figura 3. Frequência das Alterações Cromossômicas nas fases da mitose de células meristemáticas de raízes de $A$. cepa desenvolvidas em diferentes amostras de agua de poços artesianos.

\section{Discussão}

O índice mitótico permite avaliar a taxa de divisão celular, sendo um parâmetro importante na avaliação de efeitos causados por agentes químicos durante o ciclo celular ${ }^{11,12} \mathrm{~A}$ redução do crescimento radicular ${ }^{13}$ pode estar relacionada com qualquer alteração nas condições ambientais, isto levanta a suspeita que algum ou vários poluentes possam estar presentes nas amostras, pois apresentam como fonte de origem áreas margeadas por atividades de agropecuária.

As substâncias contaminantes tóxicas liberadas na água podem não mostrar efeitos agudos em organismos expostos, porém podem causar redução de sobrevivência, danos teciduais, danos genéticos de células somáticas e germinativas, acumulação de contaminantes persistentes e neoplasias ${ }^{14}$. Em geral, alterações no índice de divisão celular e do material genético podem ser deletérias para o organismo e indutoras de consequências severas e irreversíveis à saúde humana ou animal ${ }^{15}$.

Maiores IM do que os relatados no controle negativo são da indução do aumento da divisão celular, que caracteriza o dano celular, produzindo proliferação descontrolada e eventualmente causando o desenvolvimento de tumores adicionais ${ }^{16,17}$. Este fato foi identificado na amostra P3 e comprovado com resultados significativos para as anormalidades cromossômicas. 
Entretanto IM menores que os que estão no controle negativo podem indicar que o crescimento e desenvolvimento de organismos está sendo afetado por componentes nas $\operatorname{amostras}^{16,17}$ o que indicou os resultados significativos para P1 e P2 nas anormalidades de descompactação da cromatina e micronúcleo.

O aumento ou diminuição do índice mitótico pode ser um indicador relevante para monitorar níveis de poluição em ambientes contaminados, especialmente aqueles contaminados por compostos potencialmente tóxicos e citotóxicos ${ }^{18,17 .}$

Uma explicação para esse fato é que os agentes citotóxicos são capazes de atuar na célula de maneira ampla, atuando em seus compartimentos, na organização de seus componentes e, portanto, podem causar alterações morfológicas, bioquímicas e fisiológicas, afetando o ciclo celular ou resultando em apoptose ${ }^{19,20,21}$. Essas mudanças também podem levar indiretamente a mudanças no material genético.

Isso implica afirmar que a utilização de agrotóxicos tem causado uma série de problemas relacionados com a contaminação ambiental e com a saúde pública, pois ao espalhar-se no ambiente, contamina a água, o solo e os alimentos, além de permanecerem nas cadeias tróficas ${ }^{22}$. Ainda, vários agrotóxicos podem afetar o sistema reprodutivo masculino de animais e também o desenvolvimento embriofetal após exposição intrauterina, dentre as quais, destacam-se as Malformações Congênitas $(\mathrm{MC})^{23,24}$.
Resultados de contaminação de amostras de agua de vinte poços artesianos e dois córregos), em Lucas do Rio Verde e Campo Verde/ MT indicaram a presença de anomalias em uma espécie de anfíbio anuro coletado em uma das duas localidades, compatíveis com exposição a agrotóxicos ${ }^{25}$. Segundo os pesquisadores, a contaminação é devido às atividades agrícolas que estão afetando o ambiente das áreas do entorno e próximas às zonas de plantio, nomeadamente as águas superficiais (incluindo as de consumo humano) e a água das chuvas situados entre os maiores produtores de soja, milho e algodão do estado e do país.

Atividades antrópicas estão entre os fatores que contribuem para o aumento de contaminantes nos recursos hídricos, capazes de levar a propriedades mutagênicas $\mathrm{e}$ clastogênicas ${ }^{26}$. Na região oeste e sudoeste do estado do Paraná já foram constatados quinze dos seus mananciais com problemas de deterioração, onde as principais formas de poluição são: o uso de agrotóxicos advindos da atividade agrícola, dejetos suínos e das áreas urbanas, despejo de esgoto e má destinação de $\operatorname{lixos}^{27}$.

Vale ressaltar que estudos com A. cepa mostram que nem sempre a toxicidade está correlacionada com a genotoxicidade, porque alterações relacionadas com o crescimento da raiz e IM são parâmetros indicativos de citotoxicidade. Por outro lado, alterações como anomalias cromossômicas (stickiness, micronúcleos, pontes cromossômicas, entre outras), indicam genotoxicidade ${ }^{8}$ 
Diante disso, a amostra P3 indicou efeito genotóxico, mas não o citotóxico. Uma possível explicação para este resultado, pode ser a contaminação advinda das interações que ocorrem no meio ambiente e que podem levar a contaminações de águas subterrâneas.

Entretanto, vale ressaltar que o trabalho não objetivou identificar as substâncias presentes na água capazes de causar alterações citotóxicas e genotóxicas.

Os dados aqui apresentados e discutidos indicam a necessidade de novos estudos, especialmente aqueles de monitoramento de longa duração, para que possam ser solidamente avaliados os riscos do consumo das fontes de água analisadas visando estratégias de vigilância em saúde ambiental e possibilidades de recuperação da qualidade da água.

\section{Conclusão}

Os dados observados nesta pesquisa permitiram concluir que através do bioensaio utilizando o sistema teste Allium cepa foram detectados efeitos genotóxicos, citotóxicos e mutagênicos para as amostras de água de poço artesiano obtidas no município de Realeza/Pr e efeitos genotóxicos

Sugere-se outros estudos para avaliar os componentes presentes na água e identificar quais apresentam propriedades citotóxica, genotóxica e mutagênica

Relacione as conclusões com os objetivos do estudo, mas evite declarações e conclusões não qualificadas não adequadamente apoiadas pelos dados. Evite fazer declarações sobre benefícios e custos econômicos, a menos que o manuscrito inclua os dados e análises econômicos apropriados. Evite aludir ao trabalho que não foi concluído.

\section{Referências}

1. CAMPOS A, GIARETTA NL, ROTTA, M, BECEGATO V, MACHADO WCP, ONOFRE SB. Caracterização Microbiológica da água do meio rural da região sudoeste do Paraná. Revista Eletrônica do Curso de Geografia do Campus Jatái - UFG - Geoambiente On-Line. 2008 juldez;11:206-220.

2. PALUDO, D. Qualidade da água nos poços artesianos do município de Santa Clara do Sul. [s.n.]: BDU - Biblioteca Digital da UNIBATES, 2010 .

3. COSTA CL, LIMA RF, PAIXÃO GC, PANTOJA LDM. Avaliação da qualidade das águas subterrâneas em poços do estado do Ceará, Brasil. Ciências Biológicas e da Saúde. 2012 jul/dez; 33(2): 171-180.

4. SANTA CATARINA. Exploração desordenada de recursos hídricos subterrâneos no estado de Santa Catarina. 2012.

5. AMARAL LA, NADER FILHO A, ROSSI JUNIOR OD. Água de consumo humano como fator de risco à saúde em propriedades rurais. Revista de Saúde Pública. 2003 Abril; 37(4): 510-4.

6. GONÇALVES MS, KUMMER L. Práticas de educação ambiental visando o saneamento rural. In: Congresso Internacional de Tecnologias para o Meio Ambiente. Bento Gonçalves. 3. 2012.

7. COSMANN NJ, DRUNKLER DA. Agrotóxicos utilizados nas culturas de milho e soja em Cascavel - PR. Revista Eletrônica Científica Inovação e Tecnologica. 2012; 2(6): 15-32. 
8. FISKEJO G. The Allium test as a standart in environmental monitoring. Hereditas. 1985;102: 99-112.

\section{LEME DM, MARIN-MORALES MA. Allium} cepa test in environmental monitoring: A review on its application. Mutation Research. 2009 Jul/Ago; 682 (1): 71-81.

10. FISKESJO G. The Allium test - a potential standard for the assessment of enviromental toxicity. In: J. W. Gorsuch (ed.), ASTM (American Society of testing Materials) special technical publication 1216. Environ. Toxicol. Risk Assessment. 1993: 331-345.

11. SMAKA-KINCL V, STEGNARB P, LOVKAC M, TOMAND MJ. The evaluation of waste, surface and ground water quality using the Allium test procedure. Mutation Research/Genetic Toxicology. 1996; 368(34):171-179.

12. SOBRAL O, MARIN-MORALES MA, RIBEIRO R. Could contaminat induced mutations lead to a genetic diversity overestimulation? Ecotoxicology. 2013; 22: 838-846.

13. ALVIN LB, KUMMROW F, BEIJO LA, LIMA CA de A, BARBOSA S. Avaliação da citogenotoxicidade de efluentes têxteis utilizando Allium cepa L. Revista Ambiente Água. 2011; 6(2): 255-265.

14. GALINDO T, SILVA E, ROSÁRIO I. Indução de micronúcleos e toxicidade por efluente doméstico em duas populações de Bathygobius soporator (Valenciennes, 1837) (Teleostei, Gobbidae) no Litoral de Salvador (BA), Brasil. Brazilian Journal of Aquatic Science and Technology. 2012; 15(1): 1-7.

15. PERON AP, CANESIN EA, CARDOSO CMV. Potencial mutagênico das águas do Rio Pirapó (Apucarana, Paraná, Brasil) em células meristemáticas de raiz de Allium cepa L. Revista Brasileira de Biociências. 2009 Mai; 7(2): 155159.

16. HOSHINA MM. Avaliação da possível contaminação das águas do Ribeirão Claro, município de Rio Claro, pertencente à Bacia do Rio Corumbataí, por meio de testes de mutagenicidade em Allium cepa. [Dissertação]. Rio Claro: Instituto de Biociências, Universidade Estadual Paulista; 2002.

17. CARITÁ R, MARIN-MORALES MA. Induction of chromosome aberrations in the Allium cepa test system caused by the exposure of seeds to industrial effluents contamined with azo dyes. Chemosphere. 2008; 72: 722-725.

18. FERNANDES TCC, MAZZEO DEC, MARIN-MORALES MA. Mechanism of micronuclei formation in polyploidizated cells of Allium cepa exposed to trifluralin herbicide. Pesticide Biochemistry and Physiology, Massachusetts. 2007; 88: 252-259.

19. KAIOUMOVA D, SÜSAL C, OPELZ G. Induction of apoptosis in Human lymphocytes by the herbicide 2,4-dichlorophenoxyacetic acid. Human Immunology. 2001; 62: 64-74.

20. COSTA CAS, HUCK CE. Efeitos citotóxicos e biocompatibilidade de agentes clareadores usados na odontologia. Uma revisão de literatura. Revista Odontológica do Brasil Central. 2006; 15(39): 3-14.

21. CAPOBIANGO RA, VESTENA S, BITTENCOURT AHC. Alelopatia de Joanesia princeps Vell. e Casearia sylvestris Sw. sob espécies cultivadas. Revista Brasileira de Farmacognosia. 2009; 19(4): 924-930.

22. ROSA IF, PESSOA VM, RIGOTTO RM. Introdução: agrotóxicos, saúde humana e os caminhos do estudo epidemiológico. Agrotóxicos, Trabalho e Saúdevulnerabilidade e resistência no contexto da modernização agrícola no Baixo Jaguaribe/CE. Fortaleza/São Paulo: Edições UFC-Expressão Popular, p. 217-56, 2011.

23. BENÍTEZ-LEITE S, MACCHI ML, ACOSTA M. Malformaciones congénitas associadas a agrotóxicos. Revista de la Sociedad Boliviana de Pediatrí. 2009; 48(3): 204-217.

24. RIGOTTO RM, SILVA AMC, FERREIRA MJM, ROSA IF, AGUIAR ADP. Tendências de agravos crônicos à saúde associados a agrotóxicos em região de fruticultura no Ceará, Brasil. Rev Bras Epidemiol. 2013; 16(3): 76373. 
25. MOREIRA JC, PERES F, SIMÕES AC, PIGNATI WA, DORES EDC, VIEIRA SN, et al. Contaminação de águas superficiais e de chuva por agrotóxicos em uma região do estado do Mato Grosso. Ciência \& Saúde Coletiva. 2012; 17(6): 1557-1568.

26. CAZENAVE J, BACCHETTA C, PARMA MJ, SCARABOTT PA, WUNDERLIN DA. Multiple biomarkers responses in prochilodus lineatus allowed assessing changes in the water quality of salado river basin (Santa $\mathrm{Fe}$, Argentina). Enviromental Poltion. 2009; 157: 19.

27. RAGAZZON D, GRABASKI CN. Qualidade da água na região rural de Francisco Beltrão, PR, pela utilização de banco de dados: 1995 a 2005. Revista Faz Ciência. 2009; 11(13): 175-190.
Financiamento - Fundação Araucária

Data de submissão: 26/11/2019

Data de aprovação: 13/12/2019 